\title{
Sedation with inhaled agents in the ICU: what are we waiting for?
}

\author{
Jan Hendrickx ${ }^{1} \cdot$ Jan Poelaert ${ }^{2} \cdot$ Andre De Wolf $^{3}$
}

Received: 14 June 2018 / Accepted: 14 June 2018 / Published online: 15 June 2018

(c) Springer Nature B.V. 2018

Inhaled anesthetics are the most commonly used drugs to provide general anesthesia. They are delivered by means of an anesthesia machine, in which the carrier gases $\left(\mathrm{O}_{2} /\right.$ air or $\mathrm{O}_{2} / \mathrm{N}_{2} \mathrm{O}$ ) flow through a vaporizer, turning the liquid agent into vapor with appropriate partial pressures. The inspired and end-expired partial pressures are routinely measured by multi-gas analyzers. At progressively increasing partial pressures, these inhaled anesthetics, often in combination with opioids, ensure unconsciousness, immobility, and blunting of the cardiovascular stress response in the face of noxious stimuli. The dose-response curve between the measured partial pressures and these clinical end-points is steep, allowing the end-expired partial pressure to be used as an excellent indicator of the likelihood that the desired clinical end-point has been achieved, outperforming EEG derived surrogate parameters of anesthetic depth [1]. Other advantages of inhaled agents include organ-independent elimination with short context-sensitive halftimes.

The same health care provider using an inhaled anesthetic while taking care of the patient in the operating room may transfer a patient to the ICU, only to switch from the use of an inhaled agent to provide general anesthesia to a propofol infusion to sedate the patient. However, there is no intrinsic reason why the inhaled agent couldn't be continued in the ICU for sedation purposes. Although inhaled agents have been used in the ICU for treatment of status epilepticus or status asthmaticus, overall these drugs are rarely used in that setting, mainly because of habit and technological limitations. The postoperative setting may be particularly suited to use inhaled agent sedation for a few hours [2].

Jan Hendrickx

jcnwahendrickx@yahoo.com

1 Department of Anesthesiology, Intensive Care and Pain Therapy, OLV Hospital, Aalst, Belgium

2 Chair Dept Anesthesiology and Perioperative Medicine, Acute and Chronic Pain Therapy, UZ Brussel, Jette, Belgium

3 Department of Anesthesiology, Feinberg School of Medicine, Northwestern University, Chicago, IL, USA
Advanced ventilator technologies are essential in the ICU: lung-protective ventilatory modes help to minimize superimposed iatrogenic lung damage, high peak flows help to minimize the work of breathing, and synchronization of spontaneous breathing with mechanical ventilatory support facilitates weaning. While their usefulness in the operating room is the subject of several ongoing investigations, advanced ventilation modes have traditionally not been considered to be needed because the lung function of most of these patients is sufficient to withstand the well-described effects of anesthesia on lung function intraoperatively. If an ICU patient with compromised lung function does come to the operating room, (s)he generally tolerates this brief period with a less-sophisticated ventilator quite well. But an ICU ventilator cannot deliver inhaled agents unless equipped with a vaporizer that wastes significant amounts of inhaled agent due to the inherent non-rebreathing nature of the ICU ventilator. However, several technological innovations now facilitate delivery of inhaled agents to sedate ICU patients. This special issue of the Journal of Clinical Monitoring and Computing contains several manuscripts describing these new technologies.

At least three approaches exist. Option number one: use an ICU ventilator, and place a device between the endotracheal tube and patient that vaporizes agent at the Y-piece and minimizes waste by reflecting part of the exhaled agent back during the next inspiration using a charcoal filter (AnaConDa, Mirus) [3-9]; some loss is obligatory to allow the partial pressure to be decreased at a sufficiently rapid rate. Any device added at the patient-machine interface (=at the Y-piece of the breathing system) is bound to add resistance and/or dead space - and thus to increase the work of breathing. This has been explored for the reflective devices [10]; it deserves particular study if a device is to be used in children. The bronchodilatory properties of inhaled agents may offset the increased work of breathing is. Option number two: the reflective device is replaced by a vaporizer controlling the inspired concentration into a second circle system proximal of the Y-piece [11]. Option number three: use an anesthesia machine that has the ventilator modes offered by an 
ICU ventilator yet allows rebreathing of inhaled agents - an intriguing solution that remains to be explored.

This special issue of the Journal of Clinical Monitoring and Computing also contains invited manuscripts related to the delivery of inhaled agents in the ICU that otherwise fall outside the scope of the journal. Why bother with the delivery of inhaled agents in the ICU? First, the partial pressure of inhaled agents can be measured continuously in the inspired and expired gas, allowing precise titration and early detection of any potential device failure. Second, data suggest patient outcome may be improved when inhaled agents rather than intravenous sedatives are used [12]. Three, inhaled agents have an enormous safety record when used intraoperatively (barred extremely rare cases of malignant hyperthermia or hepatotoxicity). Their effects after long(er) term use in the ICU remain less well studied, but the review by Manatpon and Kofke [13] reads reassuring. Finally, ICU contamination by trace gases and its clinical significance is reviewed [14].

To summarize, inhaled anesthetic agent sedation in the ICU is coming of age, and this special issue addresses the delivery tools, the potential benefits and drawbacks, and appropriate scavenging techniques.

\section{References}

1. Avidan MS, Jacobsohn E, Glick D, et al. BAG-RECALL Research Group. Prevention of intraoperative awareness in a high-risk surgical population. N Engl J Med 2011;365:591-600.

2. Orriach JL, Aliaga MR, Ortega MG, et al. Sevoflurane in intraoperative and postoperative cardiac surgery patients. Our experience in intensive care unit with sevoflurane sedation. Curr Pharm Des. 2013;19:3996-4002.

3. Farrell R, Oomen G, Carey P. A technical review of the history, development and performance of the anaesthetic conserving device "AnaConDa" for delivering volatile anaesthetic in intensive and post-operative critical care. J Clin Monit Comput 2018 Jan 31. https://doi.org/10.1007/s10877-017-0097-9.

4. Bomberg H, Glas M, Groesdonk VH, Bellgardt M, Schwarz J, Volk T, Meiser A. A novel device for target controlled administration and reflection of desflurane-the Mirus ${ }^{\mathrm{TM}}$. Anaesthesia. 2014;69(11):1241-50. https://doi.org/10.1111/anae.12798.

5. Bomberg H, Wessendorf M, Bellgardt M, Veddeler M, Wagenpfeil S, Volk T, Groesdonk HV, Meiser A. Evaluating the efficiency of desflurane reflection in two commercially available reflectors. J Clin Monit Comput. 2016. https://doi.org/10.1007/s1087 7-016-9902-0.

6. Bomberg H, Volk T, Groesdonk HV, Meiser A. Efficient application of volatile anaesthetics: total rebreathing or specific reflection? J Clin Monit Comput. 2018. https://doi.org/10.1007/s1087 7-017-0096-x.

7. Bellgardt M, Drees D, Vinnikov V, Procopiuc L, Meiser A, Bomberg H, Gude P, Vogelsang H, Weber TP, Herzog-Niescery J. Use of the MIRUS ${ }^{\mathrm{TM}}$ system for general anaesthesia during surgery: a comparison of isoflurane, sevoflurane and desflurane. J Clin Monit Comput. 2018. https://doi.org/10.1007/s10877-018-0138-z.

8. Karnjuš I, Mekiš D, Križmarić M. Uncontrolled delivery of liquid volatile anaesthetic when using the anaesthetic conserving device. J Clin Monit Comput. 2017. https://doi.org/10.1007/s1087 7-017-0022-2.

9. Bomberg H, Meiser F, Zimmer S, Bellgardt M, Volk T, Sessler DI, Groesdonk HV, Meiser A. Halving the volume of AnaConDa: initial clinical experience with a new small-volume anaesthetic reflector in critically ill patients-a quality improvement project. J Clin Monit Comput. 2018. https://doi.org/10.1007/s1087 7-018-0146-z.

10. Chabanne R, Perbet S, Futier E, et al. Impact of the anesthetic conserving device on respiratory parameters and work of breathing in critically ill patients under light sedation with sevoflurane. Anesthesiology. 2014;121:808-16.

11. Mashari A, Fisher JA, Fedorko L, Wąsowicz M, Meineri M. Technology III. in-line vaporizer with reflector. J Clin Monit Comput. 2017. https://doi.org/10.1007/s10877-017-0078-z.

12. Bellgardt M, Bomberg H, Herzog-Niescery J, Dasch B, Vogelsang H, Weber TP, Steinfort C, Uhl W, Wagenpfeil S, Volk T, Meiser A. Survival after long-term isoflurane sedation as opposed to intravenous sedation in critically ill surgical patients: Retrospective analysis. Eur J Anaesthesiol. 2016;33:6-13.

13. Manatpon P, Kofke WA. Toxicity of inhaled agents after prolonged administration. J Clin Monit Comput. 2017. https://doi. org/10.1007/s10877-017-0077-0

14. Herzog-Niescery J, Seipp HM, Weber TP, Bellgardt M. Inhaled anesthetic agent sedation in the ICU and trace gas concentrations: a review. J Clin Monit Comput 2017. https://doi.org/10.1007/ s10877-017-0055-6 